\title{
Flyback Inverter Using Voltage Sensorless MPPT for Photovoltaic AC Modules
}

\author{
Dong-Kyun Ryu*, Bong-Yeon Choi*, Soon-Ryung Lee*, Young-Ho Kim, and Chung-Yuen Won ${ }^{\dagger}$ \\ ${ }^{*}$ † Dept. of Information and Communication Engineering, Sunkyunkwan University, Suwon, Korea
}

\begin{abstract}
A flyback inverter using voltage sensorless maximum power point tracking (MPPT) for photovoltaic (PV) AC modules is presented. PV AC modules for a power rating from $150 \mathrm{~W}$ to $300 \mathrm{~W}$ are generally required for their small size and low price because of the installation on the back side of PV modules. In the conventional MPPT technique for PV AC modules, sensors for detecting PV voltage and PV current are required to calculate the PV output power. However, system size and cost increase when the voltage sensor and current sensor are used because of the addition of the auxiliary circuit for the sensors. The proposed method uses only the current sensor to track the MPP point. Therefore, the proposed control method overcomes drawbacks of the conventional control method. Theoretical analysis, simulation, and experiment are performed to verify the proposed control method.
\end{abstract}

Keywords: AC Modules, MPPT (Maximum power point tracking), Photovoltaic power generation systems, Voltage Sensorless

\section{INTRODUCTION}

Interest in photovoltaic energy has grown nowadays in response to increased environmental concerns. A number of circuits and their control schemes for photovoltaic power generation systems have been studied [1]. A conventional system employs a PV array, in which many PV modules are connected in series or parallel to obtain sufficient DC input voltage for generating $\mathrm{AC}$ grid line voltage. However, the conventional system suffers from power loss caused by mismatch between PV modules and shadows created by trees, buildings, and other obstacles partially covering modules [2]. The latest technology for decentralized grid-connected PV systems involves PV AC modules, such as module integrated converters and micro inverters [3]-[6]. The PV AC modules are combinations of a single PV module and single-phase interactive inverter. The inverter is installed either at the back side of PV modules or support structure [7]. The benefits of this approach permit the PV AC modules to overcome the weak points of conventional systems, such as mismatch and necessity of avoiding shadows created by obstacles [8].

Manuscript received Mar. 20, 2014; accepted Jul. 23, 2014 Recommended for publication by Associate Editor Yan Xing.

†Corresponding Author: won@yurim.skku.ac.kr

Tel: +82-31-290-7115, Fax: +82-31-290-7179, Sunkyunkwan University

*Dept. of Information and Communication Eng., Sunkyunkwan

University, Korea
This paper presents the flyback inverter using voltage sensorless MPPT for PV AC modules. This topology configuration is simple. Fewer power switches are used than in other topologies for PV AC modules. MPPT has to be performed when this topology is used in PV AC modules because the output power of PV modules is changed according to weather condition [9]. For conventional PV AC modules, perturb and observe $(\mathrm{P} \& \mathrm{O})$ method or incremental conductance (INC) method is used for MPPT control. PV output power calculated by the PV voltage and PV current is required to perform these conventional MPPT methods. Hence, the voltage and current sensors are essential for sensing the PV voltage and PV current. However, PV AC modules need a low price and small size because of a power conversion system (flyback inverter) installed in the other side of PV modules. Therefore, conventional control methods are unsuitable for the PV AC modules. Unlike the conventional MPPT methods, the proposed method requires only one PV current sensor. An accumulated quantity is calculated by using the sensed PV current. In addition, quantity variation and current variation are used to calculate the PV power variation. Finally, the flyback inverter performs the MPPT through controlling PV power variation and $\mathrm{PV}$ current variation.

A novel MPPT scheme with a reduced number of sensors is presented, which has minimized overall circuit size, volume, and cost. Theoretical and operational principles are explained along with informative simulation and experimental results. 


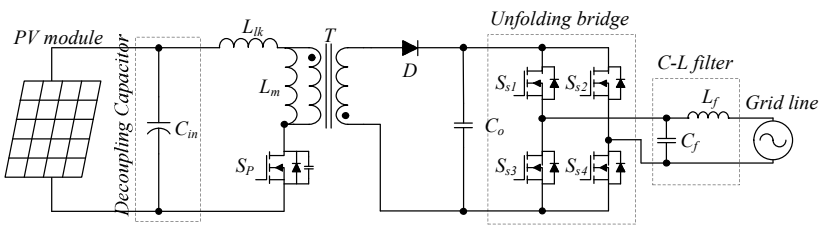

Fig. 1. Configuration of the PV flyback inverter.

\section{OPERATION OF PV FLYBACK INVERTER}

Fig. 1 shows the PV flyback inverter. The PV module is used for the input source of this inverter. The grid line is connected to the output load. This inverter consists of a decoupling capacitor, main switch, diode, unfolding bridge, output filter, and transformer. The primary switch $S_{p}$ operates with high switching frequency. Switches $S_{s I}-S_{s 4}$ of unfolding bridge operate with $50 \mathrm{~Hz}$ to $60 \mathrm{~Hz}$, which is similar to a grid line frequency. The decoupling capacitor needs to reduce ripple components of the input voltage and current because nearly constant input voltage and current are essential for MPPT technique. The flyback transformer generates the AC power and isolates the PV module and grid line to prevent electric accidents. The output filter is used to reduce the harmonic component and create a current waveform in the single-phase utility line voltage.

Fig. 3 shows the key waveforms of the flyback inverter. The grid voltage is synchronized with grid line frequency. The primary switch PWM signal is generated when the reference current $i^{*}$ ref is compared with the carrier waveform. Switches $S_{s l}$ and $S_{s 4}$ are turned on in the positive half cycle of the grid voltage and turned off in the negative half cycle, whereas switches $S_{s 2}$ and $S_{s 3}$ are turned on in the negative half cycle and turned off in the positive half cycle. The magnetizing inductor builds up energy when the primary switch $S_{p}$ is turned on. This inductor releases the energy when the $S_{p}$ is turned off. The current waveforms of $S_{s 1}-S_{s 4}$ are synchronized with the voltage of the grid line.

\section{Proposed Voltage SENSORLESS MPPT}

The PV module has nonlinear power-versus-voltage characteristics in the photovoltaic system because of temperature, aging, and possible breakdown of individual cells.

Many different MPPT techniques for photovoltaic system have been used to control nonlinear PV modules because linear control theory cannot be applied to extract the maximum electric power from the PV module. Among these different techniques, $\mathrm{P} \& \mathrm{O}$ and INC methods have the advantage of not requiring PV module characteristics [10], [11].

Fig. 4 shows a flowchart of the conventional P\&O MPPT. In this MPPT method, calculating the PV output power is necessary. Sensing the PV voltage and current requires individual sensors. However, each sensor increases the system size, volume, and cost in the PV AC modules because
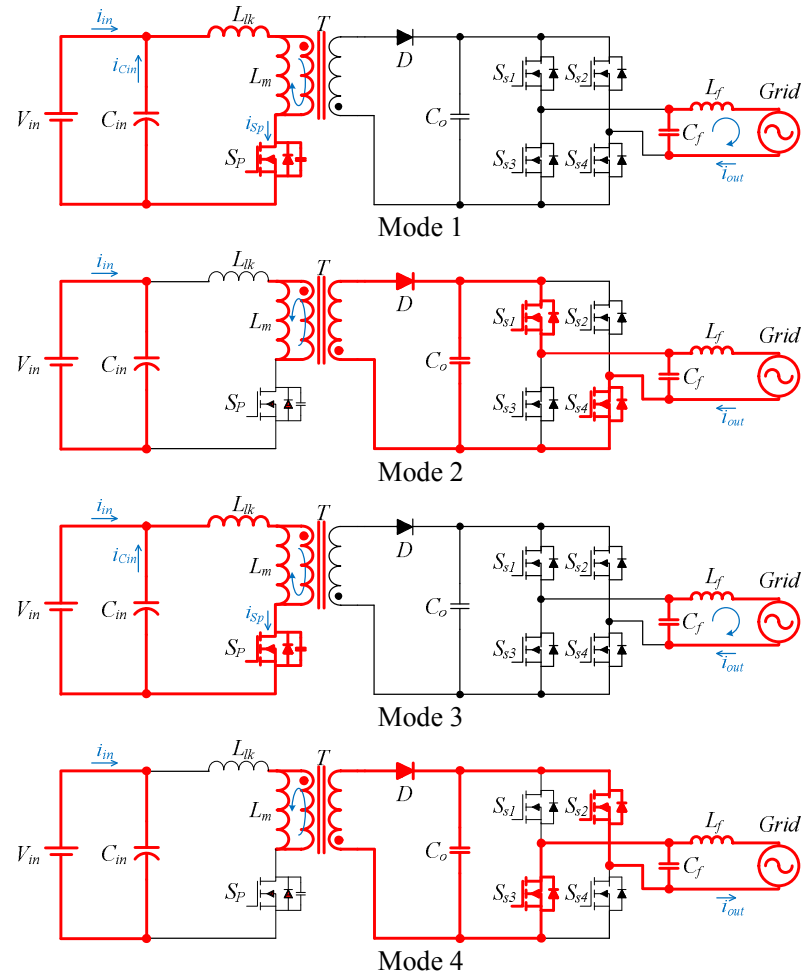

Fig. 2. Mode transitions of the PV flyback inverter.

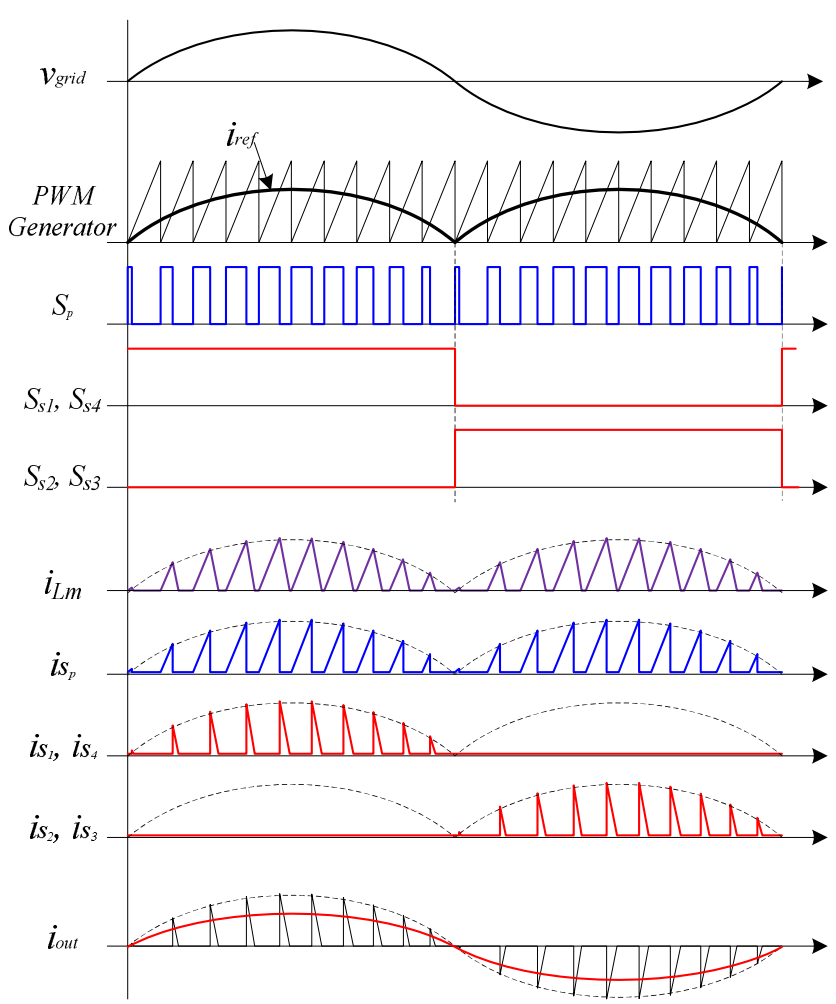

Fig. 3. Key waveforms of the flyback inverter.

of the additional devices and peripheral circuit for PV sensors. Voltage sensorless MPPT is proposed to overcome these problems.

Fig. 5 shows a flowchart of the proposed voltage sensorless MPPT method. The proposed MPPT technique needs only 


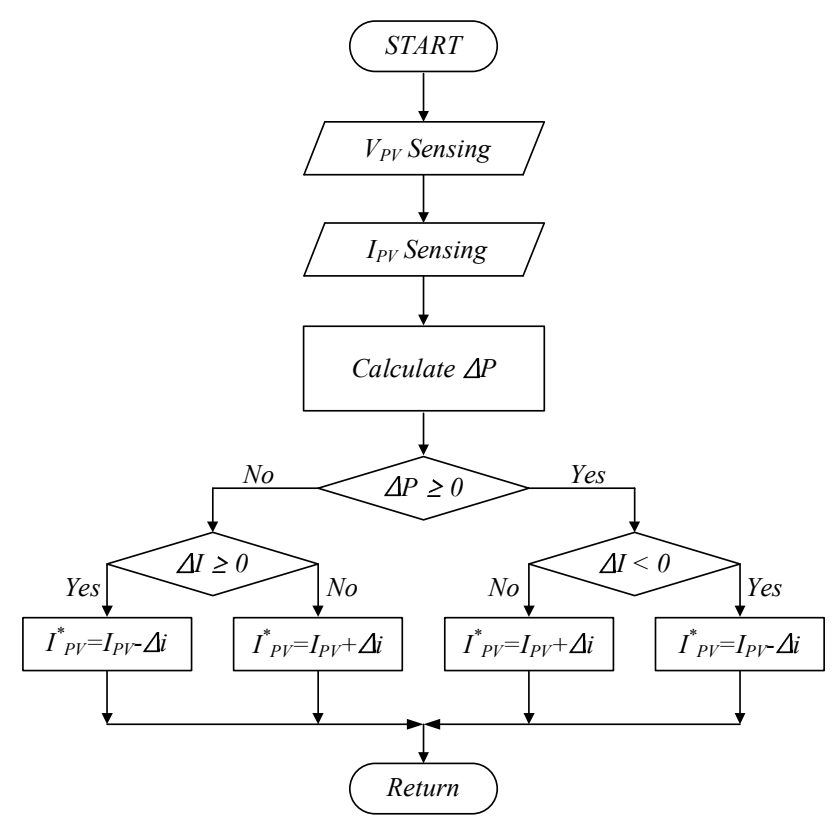

Fig. 4. Flowchart of conventional P\&O MPPT method.

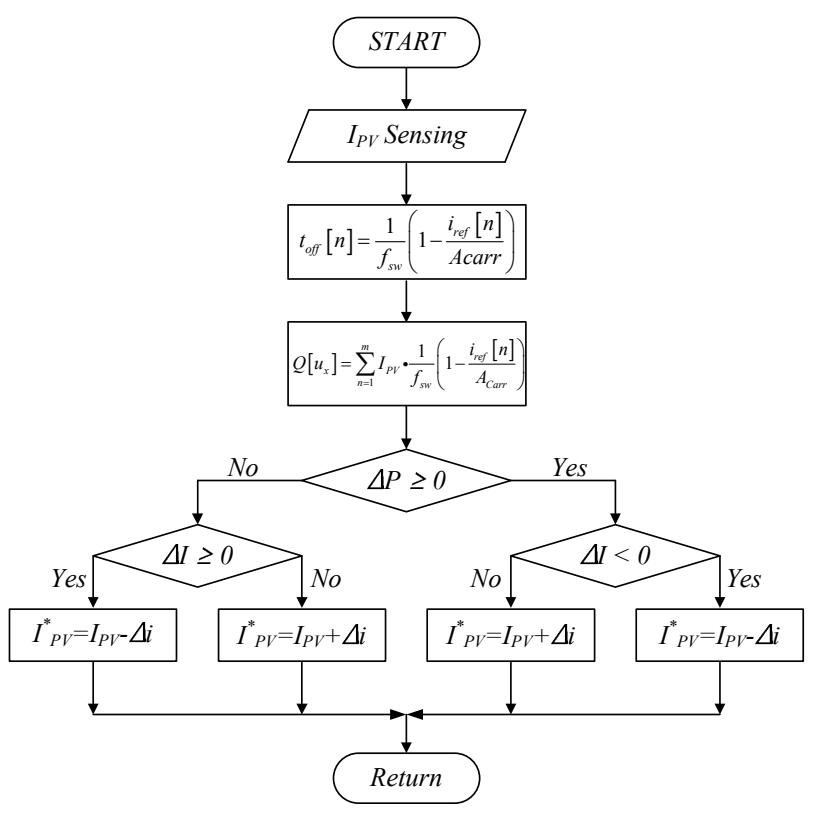

Fig. 5. Flowchart of proposed voltage sensorless MPPT method.

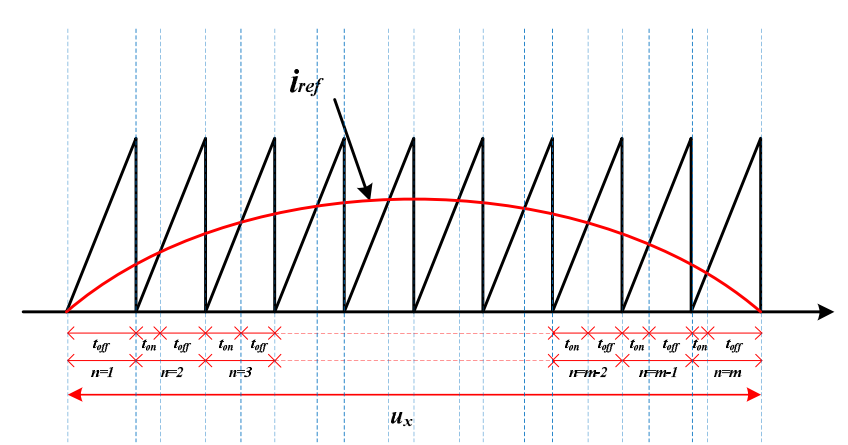

Fig. 6. Analysis of proposed voltage sensorless MPPT during primary switch transition. one input sensor. In this flowchart, the PV current is sensed to calculate the PV power variation. Moreover, the off-time is calculated. The quantity variation during half period at grid line is also calculated by using the PV current and calculated off-time. Subsequently, the PV current multiplied with the quantity variation is identified as the power variation. The power variation is compared with zero, such as P\&O MPPT, in Fig. 4.

To calculate the off-time in Fig. 5, the switching time $T$ is considered equal to the sum of the on-time and off-time.

Fig. 6 shows the following:

$$
\begin{gathered}
t_{\text {off }}[n]=T-t_{\text {on }}[n] \\
t_{\text {off }}[n]=\frac{1}{f_{\text {sw }}}\left(1-\frac{i_{\text {ref }}[n]}{A_{\text {carr }}}\right)
\end{gathered}
$$

Eq. (2) shows that $f_{s w}$ is defined as the primary switching frequency, $A_{\text {carr }}$ is defined as the magnitude of the carrier waveform, and $i_{\text {ref }}$ * is defined as the reference current during the $n$th switching period.

The energy charge from the PV array during off-time of the primary switch is equal to the electric charge emitted from the input capacitor during the on-time of the primary switch.

$$
\begin{gathered}
\Delta q\left[t_{o n}\right]=\Delta q\left[t_{o f f}\right] \\
\Delta q=I_{p v}\left(T-t_{o n}[n]\right)
\end{gathered}
$$

We obtain the following when Equation (4) is integrated over the interval $u_{x}$ of the switching period shown in Fig. 6(c):

$$
\sum_{n=1}^{m} \Delta q_{n}=\sum_{n=1}^{m} i_{P V} t_{o f f}[n]
$$

Eq. (5) shows that the total amount of electric charge that flows out of the PV array in the off-time during the $u_{x}$ period is defined as $Q\left[u_{x}\right]$ and expressed as follows:

$$
Q\left[u_{x}\right]=\sum_{n=1}^{m} i_{P V} \frac{1}{f_{s w}}\left(1-\frac{i_{r e f}[n]}{A_{\text {Carr }}}\right)
$$

Fig. 7 shows waveforms of the primary switch and secondary switches $S_{2}$ and $S_{3}$ obtained for comparison between the carrier waveform and waveform of the reference current $i^{*}{ }_{r e f}$ during the $u_{x}$ th switching period. When $Q\left[u_{x-I}\right]$ and $Q\left[u_{x}\right]$ are defined as the total amount of electric charge during the off-time at the end of the $u_{x-1}$ th and $u_{x}$ th periods, respectively, the variable electric charge between the $Q\left[u_{x-1}\right]$ and $Q\left[u_{x}\right]$ is expressed as follows:

$$
\Delta Q=Q\left[u_{x}\right]-Q\left[u_{x-1}\right]
$$




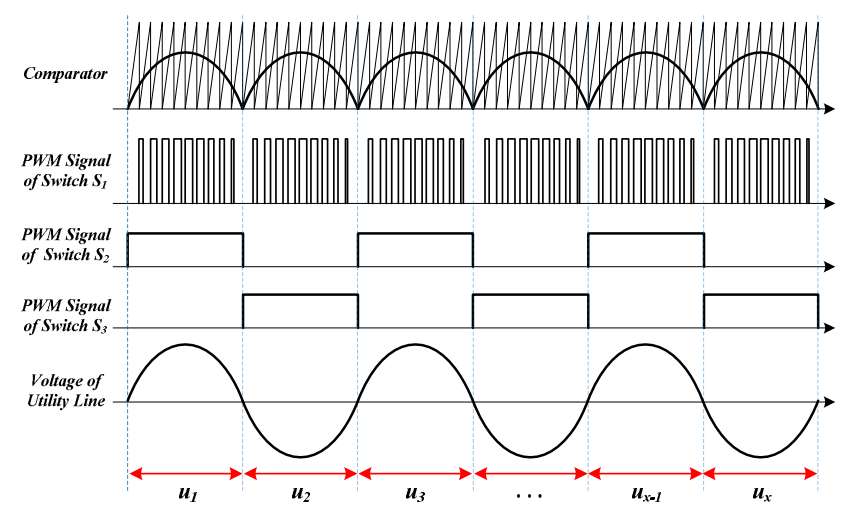

Fig. 7. Main switch waveforms of the flyback inverter.

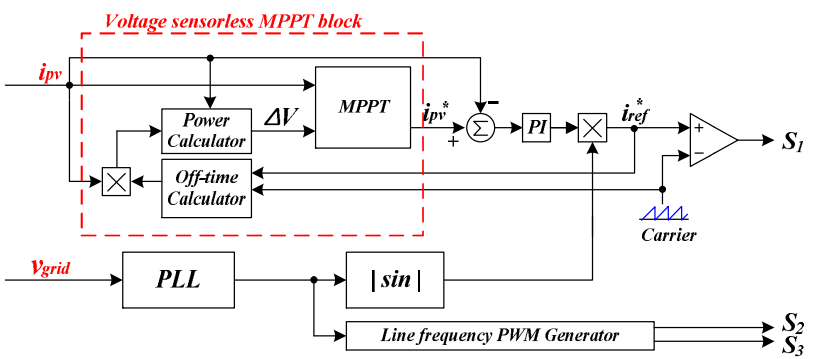

Fig. 8. Proposed voltage sensorless MPPT control block diagram.

Finally, the variable PV voltage can be estimated as follows:

$$
\Delta V=\frac{\Delta Q}{C}
$$

The current perturbation is computed for P\&O MPPT after calculating the PV power by using the calculated PV voltage variation and sensed $\mathrm{PV}$ current. The signs of $\Delta P$ and $\Delta I$ are useful in deciding the direction in which the perturbation is applied in Fig. 5.

Fig. 8 shows the proposed voltage sensorless MPPT control block diagram. In the grid-connected mode of operation, a fast and accurate phase-locked-loop (PLL) method is essential for the reference current $i^{*}{ }_{\text {ref }}$. In addition, the PLL is used to generate the rectified waveform synchronized grid voltage. The secondary switches are controlled by a PWM signal calculated by the grid line frequency PWM generator using PLL output signal. Switch $S_{2}$ is turned on in the positive half cycle of the grid voltage. Switch $S_{3}$ is turned on in the negative half cycle of the grid voltage in Fig. 7. The resulting signal of the absolute sine generator is calculated by the PLL output signal. The off-time calculator calculates the off-time by using the carrier magnitude, switching frequency, and resulting signal of the absolute sine generator. This calculated off-time is multiplied by the PV current. The voltage calculator generates a variable voltage by using the PV current and the multiplied signal. The MPPT controller calculates the PV reference current by using the PV current and the variable voltage. When this signal is compared with

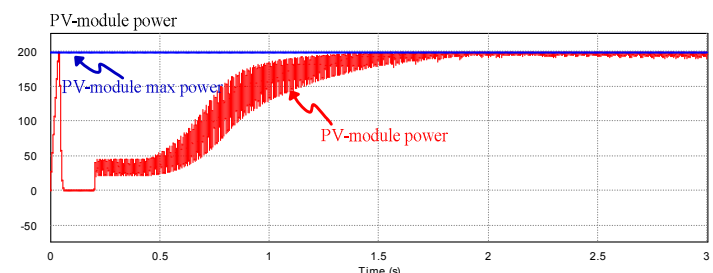

(a)

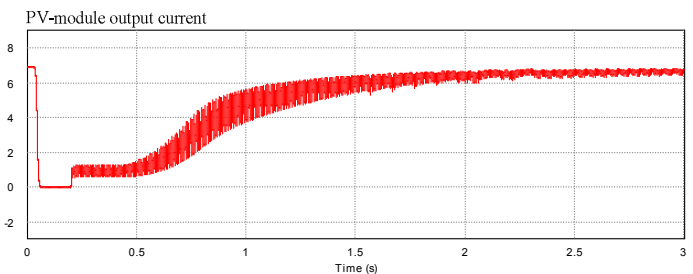

(b)

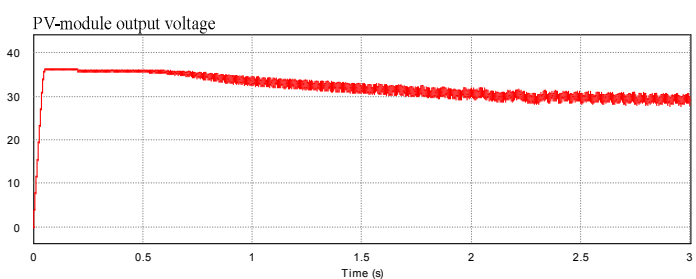

(c)

Fig. 9. Simulation results of flyback inverter using conventional MPPT control method.

the PV current, the error signal enters a PI controller. When the resulting signal of the PI controller is multiplied by the resulting signal of the absolute sine generator, the reference current $i^{*}{ }_{r e f}$ is calculated. Finally, the primary switch is controlled by using the reference current $i^{*}{ }_{r e f}$ and the carrier waveform.

\section{SiMULATION RESULTS}

Simulation results are presented in Figs. 9-10 produced with PSIM 9.0 software to verify the theoretical analysis of the proposed voltage sensorless MPPT in a flyback inverter. The PV module is modeled by C-language-based DLL blocks in this simulation. The experiment was simulated and tested by using a $200 \mathrm{~W}$ cell module.

Fig. 9 shows the simulation results of flyback inverter using conventional P\&O MPPT control method. Fig. 9(a) shows that the output power of PV module tracked the PV-module maximum power. Figs. 9(b) and (c) show that output voltage and current of PV module are controlled to track the MPP.

Fig. 10 shows the simulation results of flyback inverter using the proposed voltage sensorless MPPT control method. Fig. 10(a) shows that the output power of PV module tracked the PV-module maximum power. Fig. 9(b) shows that the output current of PV module is controlled for tracking the MPP. Fig. 10(c) presents the change amount of charge in decoupling capacitor $C_{i n}$ calculated from voltage sensorless MPPT control method. The amount of charge in $C_{i n}$ is 


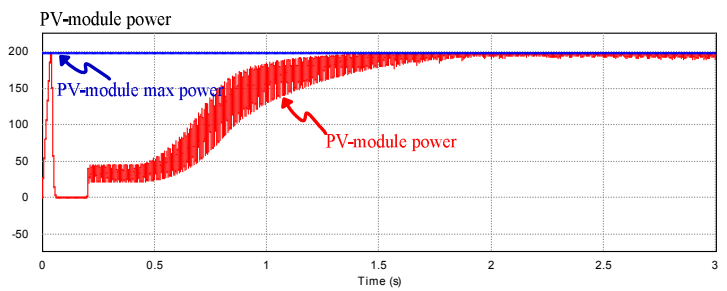

(a)

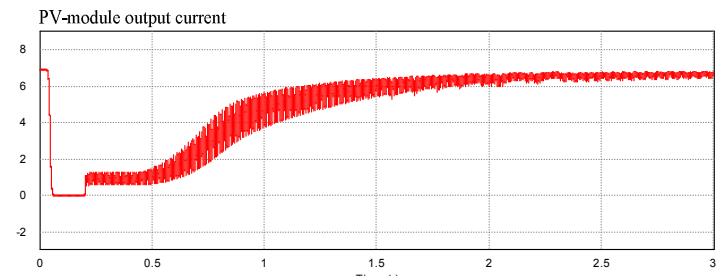

(b)

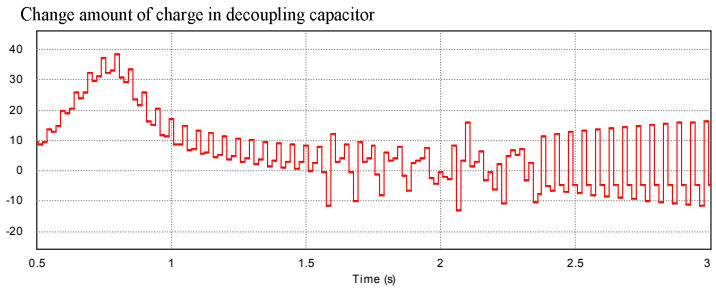

(c)

Fig. 10. Simulation results of flyback inverter using the proposed MPPT control method.

constantly changed in the maximum power point $(2.5$ second point).

Fig. 11 shows the simulation results using proposed voltage sensorless MPPT under partial shading condition. Periods 1 and 3 used $1000 \mathrm{~W} / \mathrm{m}^{2}$ irradiation condition. Output power is decreased by partial shading in period 2 . Fig. 11(a) to 11 (d) are simulation results when irradiation is decreased per $20 \%$ by partial shading. The simulation results show that the proposed voltage sensorless MPPT control stably tracks maximum power point under partial shading condition.

These simulation results indicate that when the conventional method is compared with the proposed method, the MPP point-tracking ability of the proposed MPPT method using only one input current sensor is almost the same as that of the conventional MPPT method.

\section{EXPERIMENTAL RESULTS}

A $200 \mathrm{~W}$ laboratory prototype is implemented to verify the performance of the proposed method.

Fig. 12(a) shows the front side of the flyback inverter, which consists of an input capacitor, transformer, filter inductor, EMI filter, DSP TMS320F28035, filter capacitor, a DC-DC converter for the voltage sensorless peripheral circuit, 2 diodes, 4 switches, an $\mathrm{RC}$ snubber, a peripheral circuit for sensing the grid voltage, and a peripheral circuit for sensing the input voltage sensor. The peripheral circuit for the input

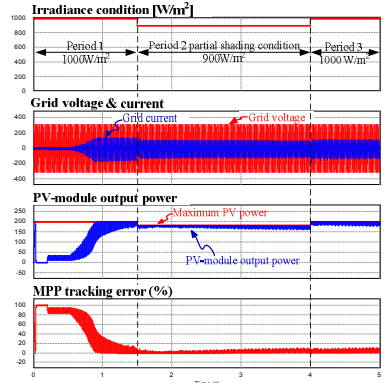

(a)

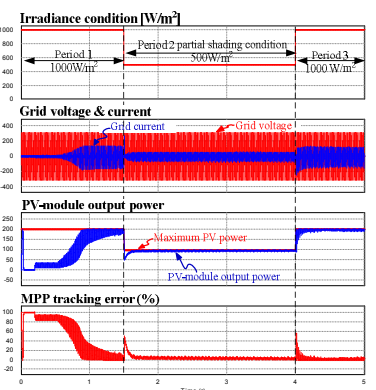

(c)

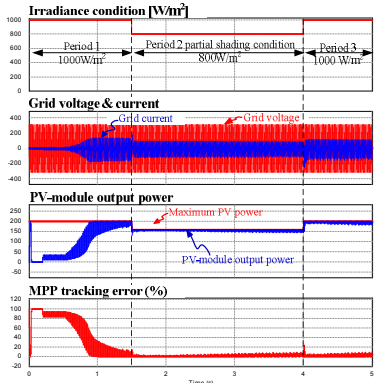

(b)

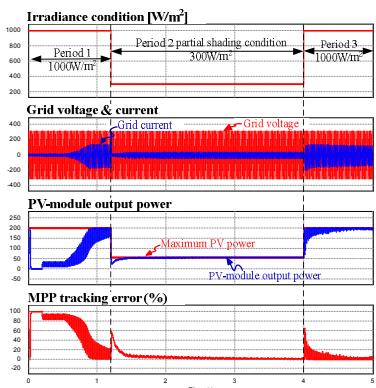

(d)
Fig. 11. Simulation results of the flyback inverter using the proposed voltage sensorless MPPT under partial shading condition, (a) 90\% irradiance, (b) 70\% irradiance condition, (c) $50 \%$ irradiance condition, (d) $30 \%$ irradiance condition.

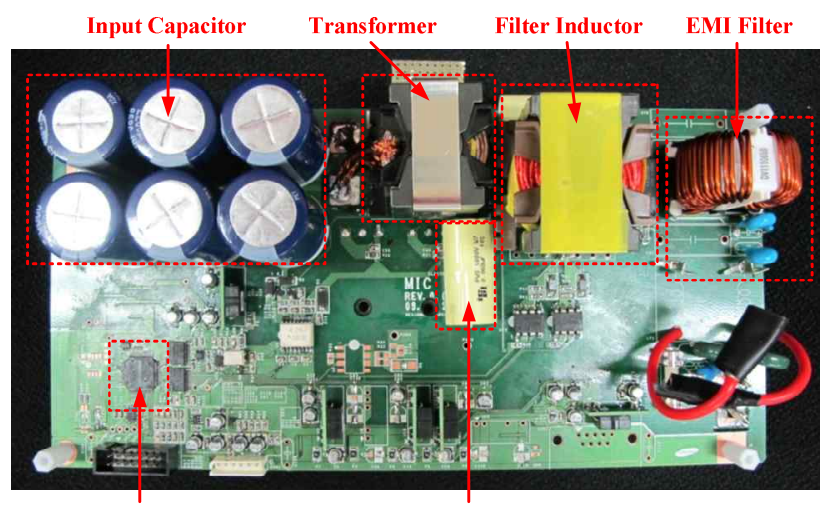

DSP(TMX320F28035)

Filter Capacitor

(a) Front side of flyback inverter experimental setup.

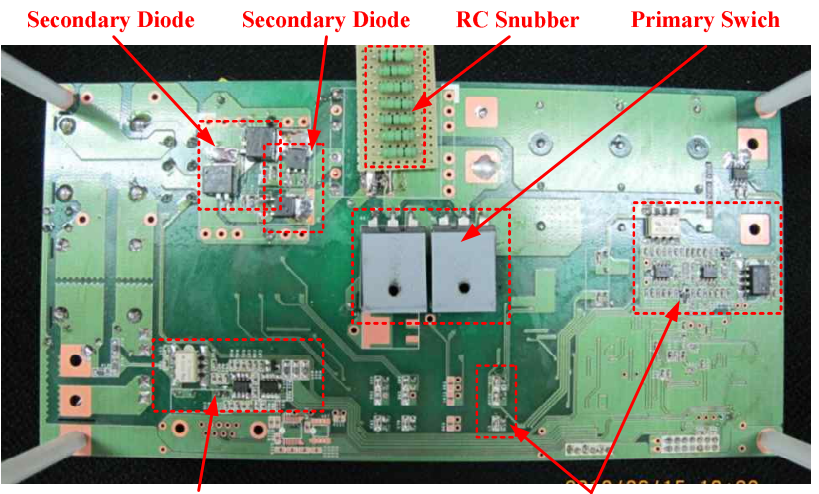

Peripheral Circuit for Grid Voltage Sensor $\quad$ Peripheral Circuit for Input Voltage Sensor

(b) Back side of flyback inverter experimental setup.

Fig. 12. Flyback inverter test bed used in this experiment. 
TABLE I

Simulation AND EXPERIMENTAL PARAMETERS OF THE FLYBACK INVERTER USING VOLTAGE SENSORLESS MPPT

\begin{tabular}{l|c|c}
\hline \multicolumn{1}{c|}{ Parameter } & Symbol & Value \\
\hline \hline INPUT VOLTAGE & $v_{\text {in }}$ & $30-45[\mathrm{~V}]$ \\
\hline OUTPUT VOLTAGE & $v_{\text {out }}$ & $220\left[\mathrm{~V}_{\mathrm{rms}}\right]$ \\
\hline INPUT POWER & $P$ & $200[\mathrm{~W}]$ \\
\hline MAGNETIZING INDUCTANCE & $L_{m}$ & $12[\mu \mathrm{H}]$ \\
\hline LEAKAGE INDUCTANCE & $L_{l k}$ & $0.3[\mu \mathrm{H}]$ \\
\hline INPUT CAPACITANCE & $C_{\text {in }}$ & $13.2[\mathrm{mF}]$ \\
\hline FILTER INDUCTANCE & $L_{f}$ & $5[\mathrm{mH}]$ \\
\hline FILTER CAPACITOR & $C_{f}$ & $47[\mathrm{nF}]$ \\
\hline SNUBBER RESISTANCE & $R_{S B}$ & $10[\Omega]$ \\
\hline SNUBBER CAPACITANCE & $C_{S B}$ & $68[\mathrm{nF}]$ \\
\hline SWITCHING FREQUENCY & $f_{s w}$ & $50[\mathrm{kHz}]$ \\
\hline GRID FREQUENCY & $f_{\text {grid }}$ & $60[\mathrm{~Hz}]$ \\
\hline
\end{tabular}

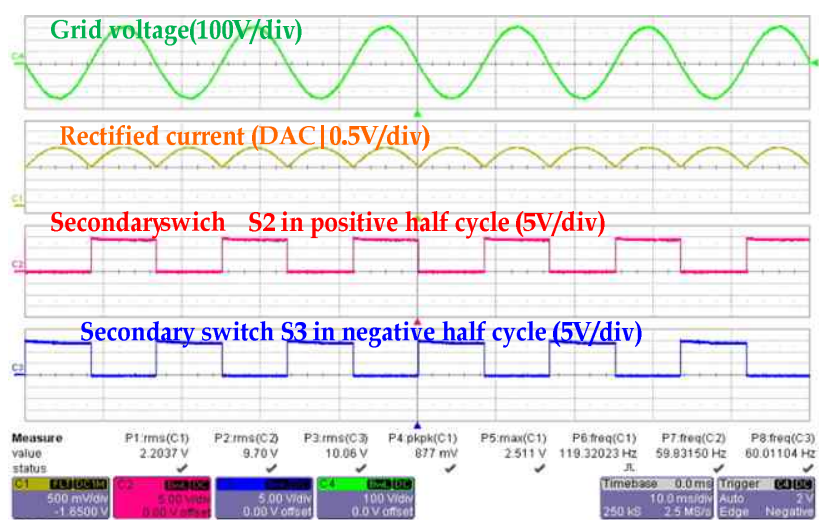

(a) Main switch waveforms of the primary stage.

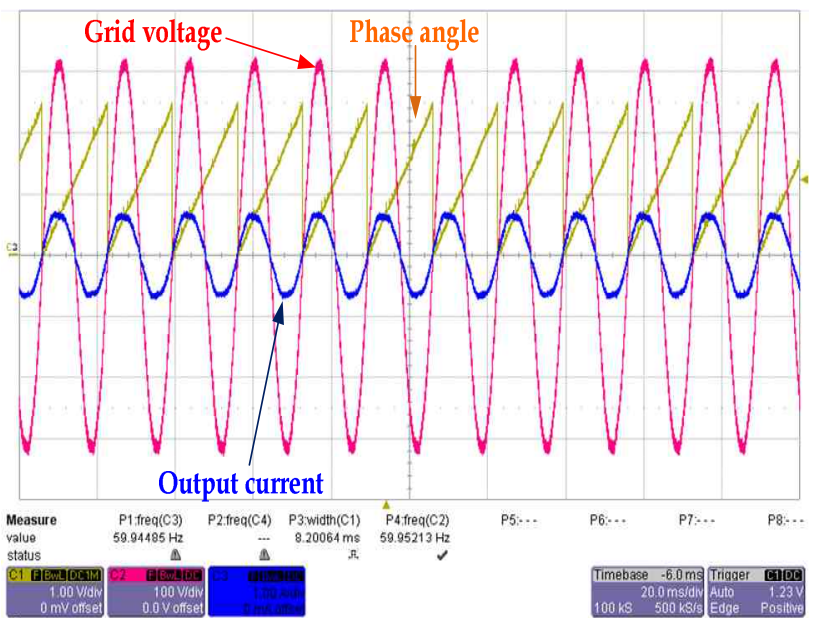

(b) Output waveforms of the secondary stage.

Fig. 13. Key waveforms of the flyback inverter using the proposed voltage sensorless MPPT method.

voltage sensor can be reduced when the proposed voltage sensorless MPPT method is used. Therefore, the system size, volume, and cost can be reduced. In this system, DSP TMX320F28035 (Texas Instruments) is used as the main controller. The system parameters are presented in Table I.

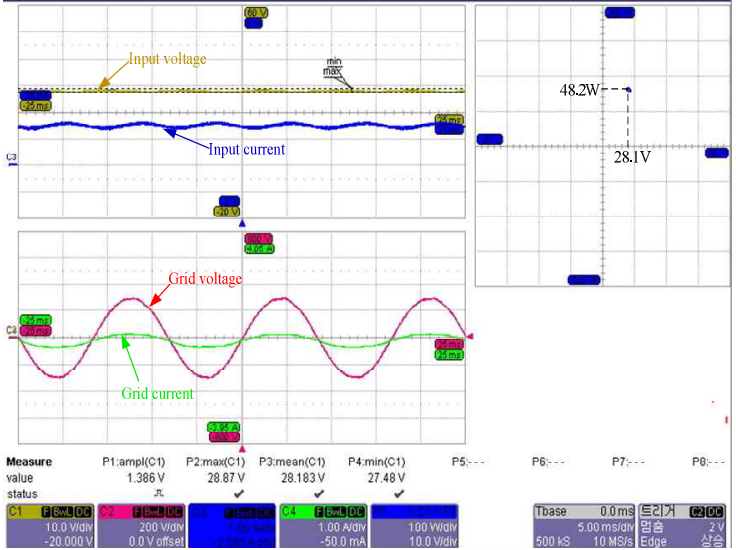

(a) $50 \mathrm{~W}$ input power condition.

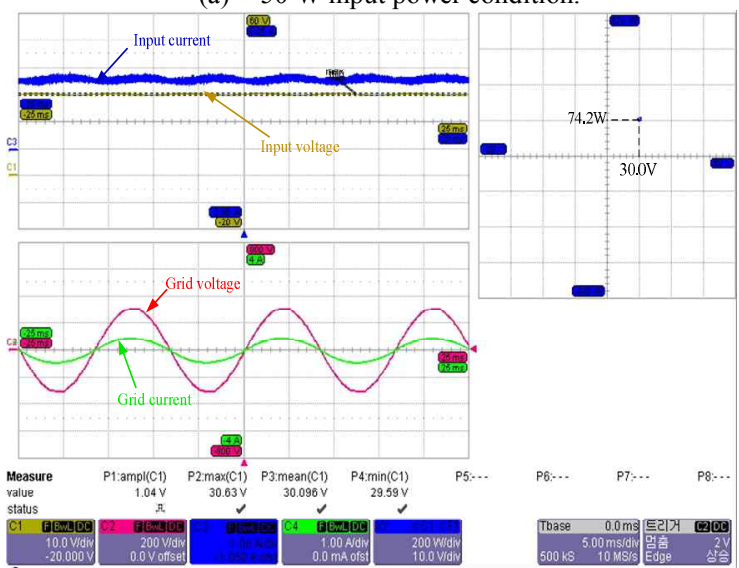

(b) $75 \mathrm{~W}$ input power condition.

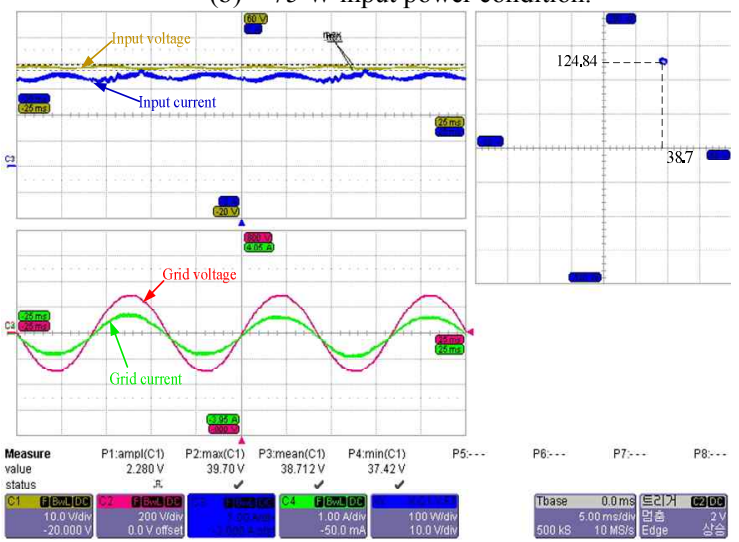

(c) $125 \mathrm{~W}$ input power condition.

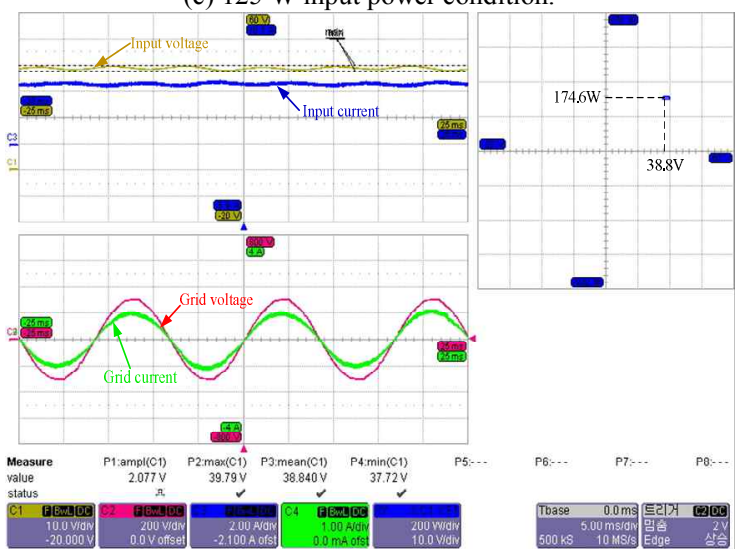

(d) $175 \mathrm{~W}$ input power condition. 


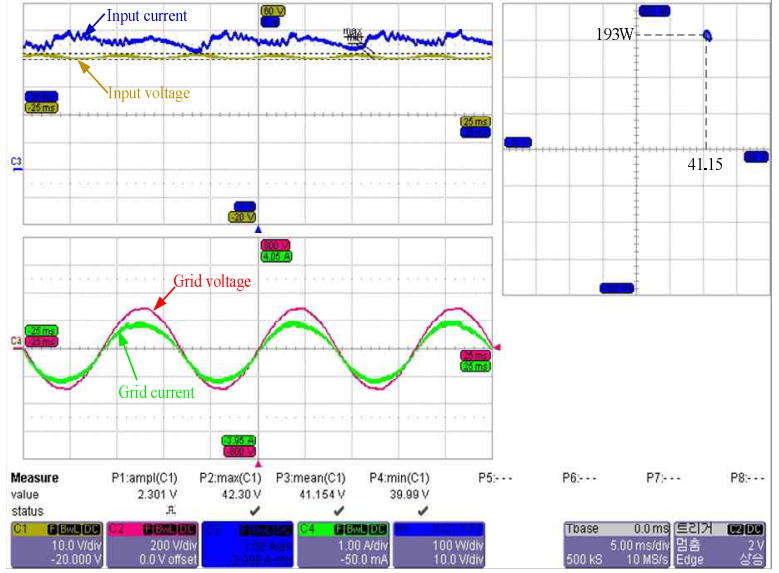

(e) $200 \mathrm{~W}$ input power condition.

Fig. 14. Experimental results of flyback inverter using conventional P\&O MPPT method according to PV module power.

In this experiment, a $480[\mathrm{~W}]$ solar array simulator (Agilent) is used as PV array and a grid line is used as output load.

Fig. 13 shows the experimental results of the key waveforms of the flyback inverter. Fig. 13(a) shows the grid voltage, rectified current, and PWM signals of secondary switches $S_{2}$ and $S_{3}$. The rectified current and secondary switches are synchronized with the grid voltage. Fig. 13(b) shows the output waveforms of the secondary stage. In this figure, the output current and phase angle are synchronized with the grid voltage.

Fig. 14 shows the experimental results of the flyback inverter using conventional P\&O MPPT method according to PV module power. Fig. 15 shows the experimental results of flyback inverter using the proposed voltage sensorless MPPT method based on PV module power. The input power comparison between Figs. 14 and 15 confirms that the MPP point-tracking ability of the proposed MPPT method using only one input current sensor is almost the same as that of the conventional MPPT method. The proposed method can reduce system size, volume, and cost. Consequently, the proposed MPPT method would be effective in PV AC modules and building integrated photovoltaic systems.

Dynamic tracking performance is investigated through PV simulator when irradiation is changed to $30 \%, 50 \%$, and $70 \%$ on PV module.

Fig. 16 shows the experimental results of the conventional P\&O MPPT. MPPT control and supplement current to grid are stably performed according to changing irradiation.

Fig. 17 shows the experimental results of the proposed MPPT method. Irradiation is also changed to $30 \%, 50 \%$, and $70 \%$ through a PV simulator. Consequently, maximum power point is tracked by the proposed MPPT same as the conventional MPPT using a voltage sensor.

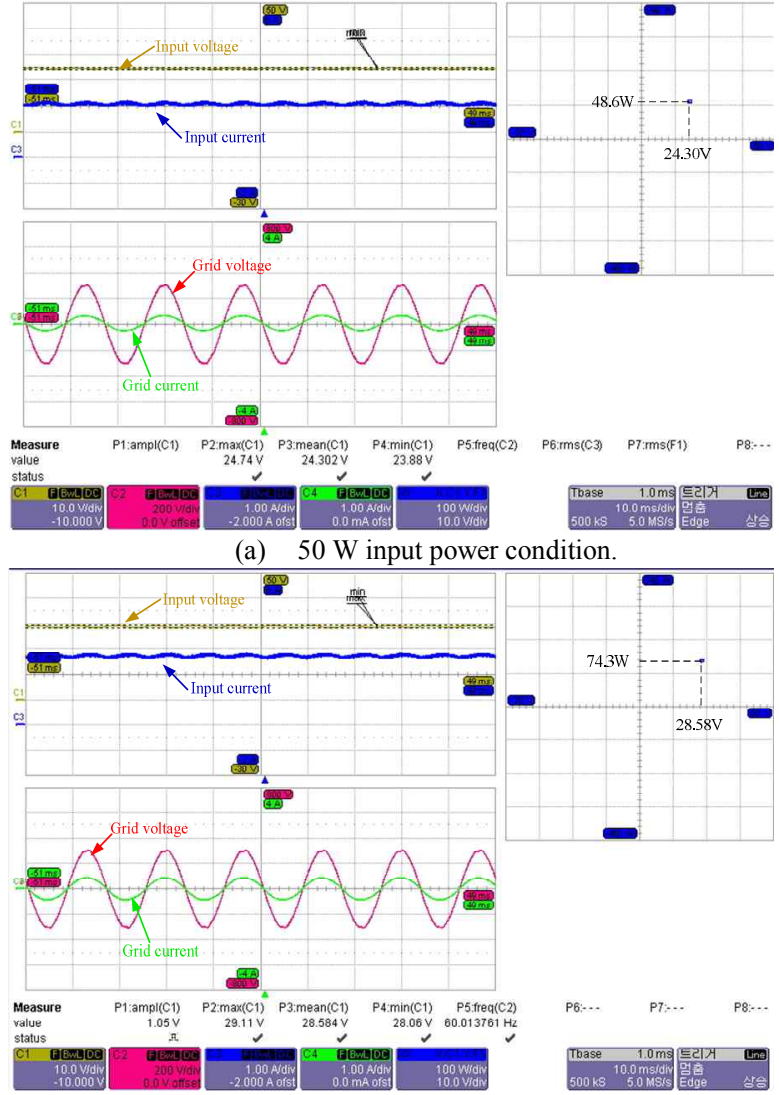

(b) $75 \mathrm{~W}$ input power condition.

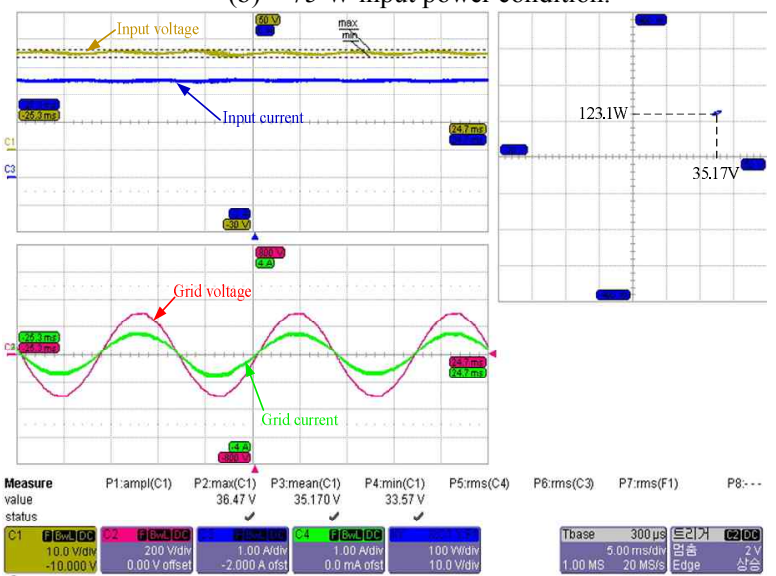

(c) $125 \mathrm{~W}$ input power condition.

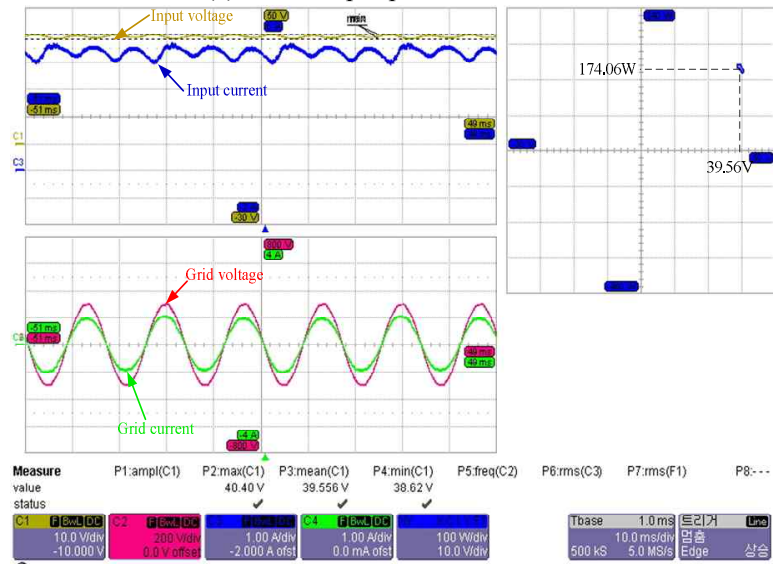

(d) $175 \mathrm{~W}$ input power condition. 


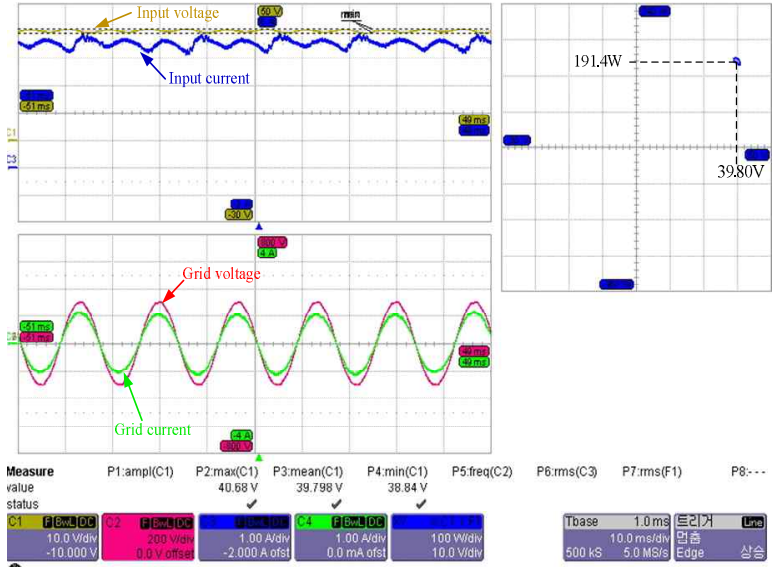

(e) $200 \mathrm{~W}$ input power condition

Fig. 15. Experimental results of flyback inverter using proposed voltage sensorless MPPT method according to PV module power
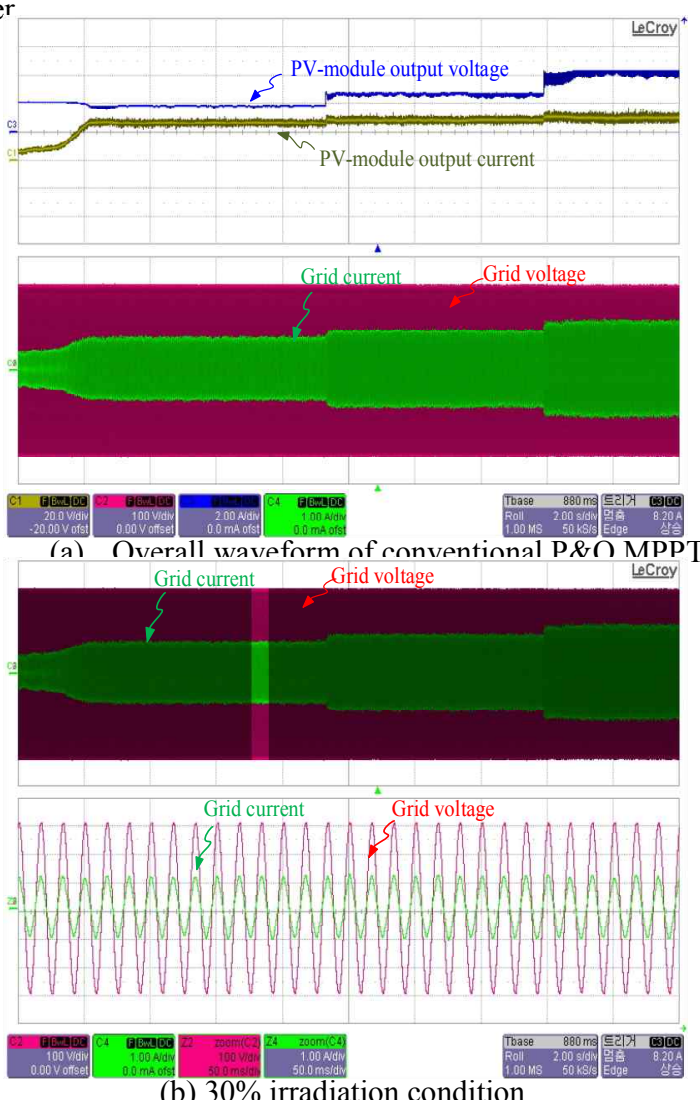

(b) $30 \%$ irradiation condition.
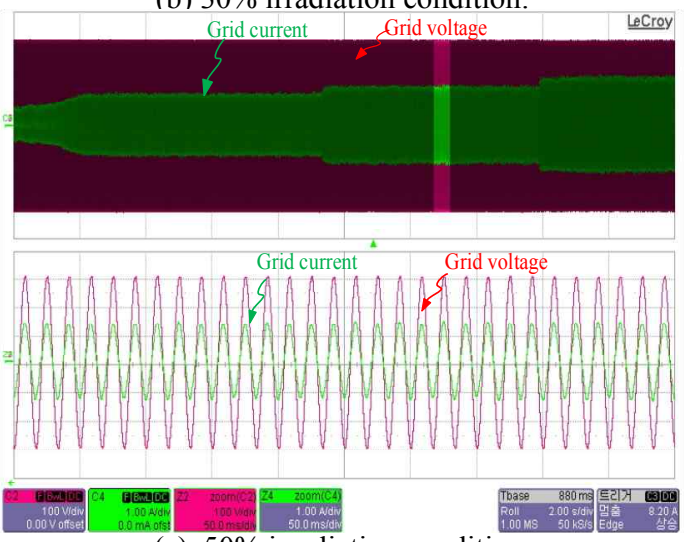

(c) $50 \%$ irradiation condition.

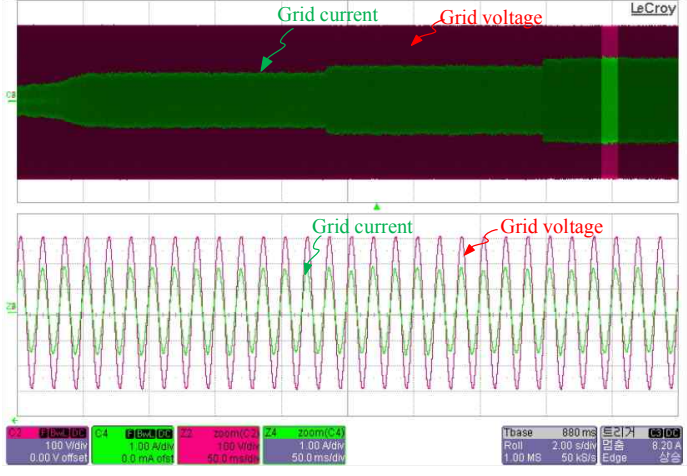

(d) $70 \%$ irradiation condition.

Fig. 16. Experimental results of the flyback inverter using conventional P\&O MPPT method under various irradiation conditions.

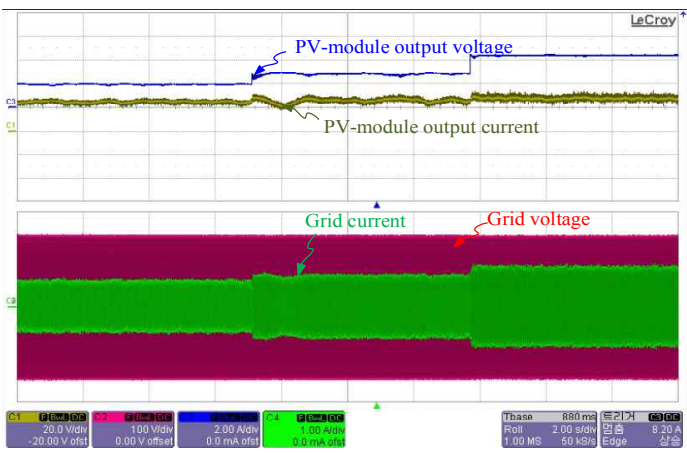

(a) Overall waveform of the proposed sensorless MPPT.
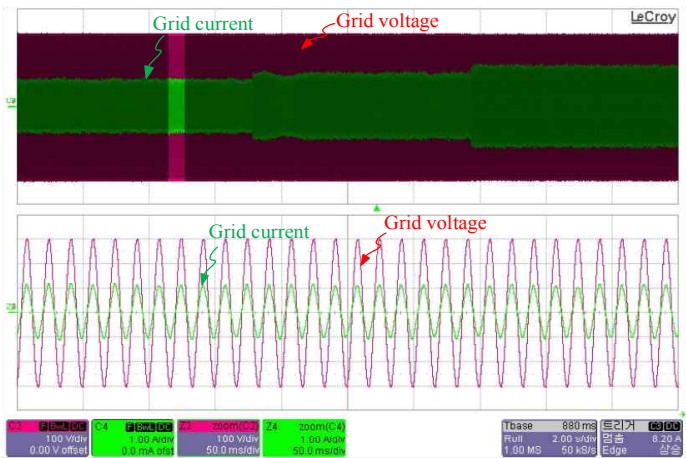

(b) $30 \%$ irradiation condition
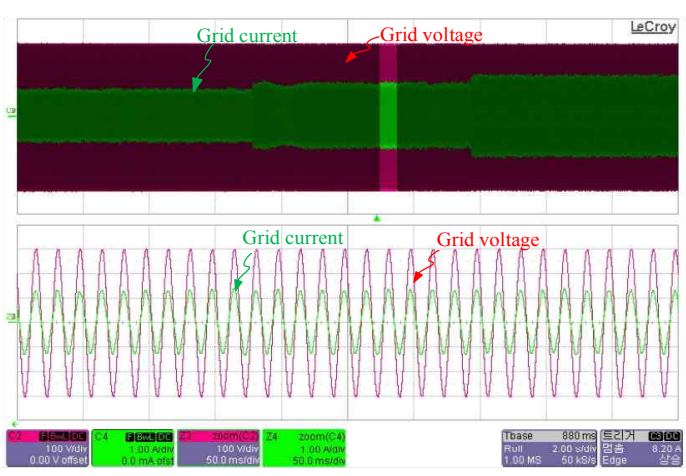

(c) $50 \%$ irradiation condition 


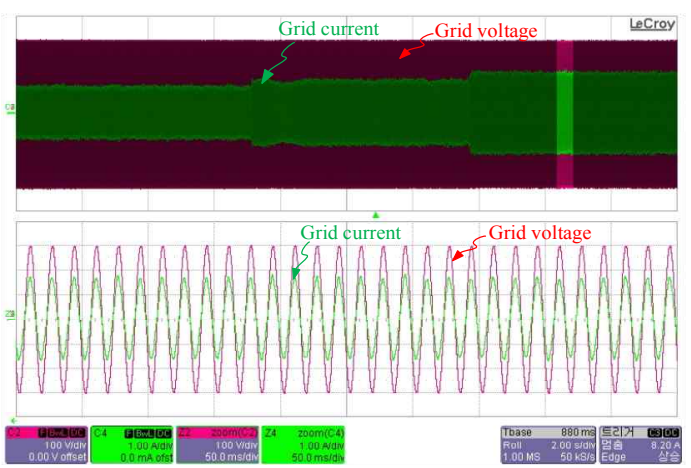

(d) $70 \%$ irradiation condition

Fig. 17. Experimental results of flyback inverter using the proposed voltage sensorless MPPT method under various irradiation conditions.

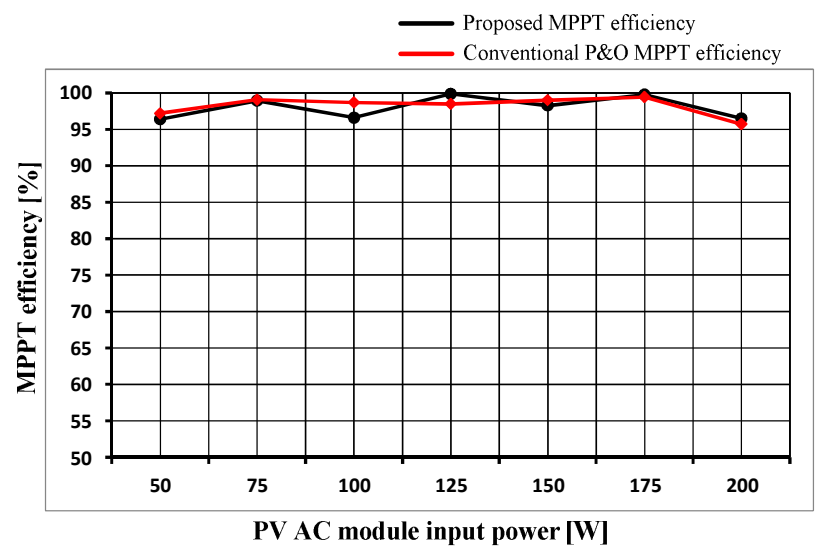

Fig. 18. MPPT efficiency comparison of conventional P\&O and proposed voltage sensorless MPPT control methods.

Fig. 18 shows the experimental results of the flyback inverter using the conventional and proposed MPPT methods shown in Figs. 1 and 2. The operating point in different load conditions is also shown. The experimental results revealed that the proposed MPPT efficiency is approximately $96 \%$ to 99\%, as shown in Fig. 3. This MPPT efficiency is similar to that of the conventional method.

\section{CONCLUSIONS}

This paper proposed a flyback inverter using voltage sensorless MPPT for photovoltaic AC modules. The circuit topology, modulation technique, and operational principles of the proposed MPPT are analyzed in detail. The voltage sensorless MPPT is implemented in a DSP TMX320F 28035 to optimize the performance of the flyback inverter. A comparison between the proposed voltage sensorless MPPT method and the conventional P\&O MPPT method reveals the same maximum power point.

The proposed flyback inverter can reduce system size, volume, and cost because of the reduced number of sensors. Simulation and experimental results show that the proposed flyback inverter can be applied to MPPT for photovoltaic AC modules with successful performance.

\section{REFERENCES}

[1] S. B. Kjaer, J. K. Pedersen, and F. Blaabjerg, "Power inverter topologies for photovoltaic modules-a review," IEEE IAS Annu. Meeting, Vol. 2, pp. 782-788, 2002.

[2] T. Shimizu, K. Wada, and N. Nakamura, "Flyback-type single-phase utility interactive inverter with power pulsation decoupling on the DC input for an AC photovoltaic module system," IEEE Trans. Power. Electron., Vol. 21, No. 5, pp.1264-1272, Sep. 2006.

[3] N. Kasa and T. Iida, "A transformer-less single phase inverter using a buck-boost type chopper circuit for photovoltaic power system," ICPE'98, pp. 978-981, 1998.

[4] N. Kasa, T. Iida, and H. Iwamoto, "An inverter using buck-boost type chopper circuits for popular small-scale photovoltaic power system," IEEE IECON'99, Vol. 1, pp. 185-190, 1999.

[5] N. Kasa, T. Iida, and H. Iwamoto, "Maximum power point tracking with capacitor identifier for photovoltaic power system," IEE Proc. Electr. Power Appl., Vol. 147, No. 6, pp. 497-502, Nov. 2000.

[6] T. Shimizu, N. Nakamura, and K. Wada, "A novel flyback-type utility interactive inverter for AC module systems," ICPE'01, pp. 518-522, 2001.

[7] A. Ch. Kyritsis, E. C. Tatakis, and N. P. Papanikolaou, "Optimum design of the current-source flyback inverter for decentralized grid-connected photovoltaic systems," IEEE Trans. Energy Convers., Vol. 23, No. 1, pp. 281-293, Mar. 2008.

[8] N. Kasa, T. Iida, and H. Iwamoto, "Maximum power point tracking with capacitor identifier for photovoltaic power system," IET Proc. Power. Appl., Vol. 147, No. 6, pp. 497-502, Nov. 2000.

[9] N. Kasa, T. Iida, and L. Chen, "Flyback inverter controlled by sensorless current MPPT for photovoltaic power system," IEEE Trans. Ind. Elec., Vol. 52, No. 4, pp. 1145-1152, Aug. 2005.

[10] T. Esram and P. L. Chapman, "Comparison of photovoltaic array maximum power point tracking techniques," IEEE Trans. Energy Conversion, Vol. 22, No. 2, pp. 439-449, Jun. 2007.

[11] J.-M. Kwon, B.-H. Kwon, and K.-H. Nam, "Three-phase photovoltaic system with three-level boosting MPPT control," IEEE Trans. Power Electron., Vol. 23, No. 5, pp. 2319-2327, Sep. 2008.

[12] J.-W. Choi, Y.-K. Kim, and H.-G. Kim, "Digital PLL control for single-phase photovoltaic system," IET Proc. Electric Power Application, Vol. 153, No. 1, pp. 40-46, Jan. 2006.

[13] T. Shimizu, K. Wada, and N. Nakamura, "A flyback-type single phase utility interactive inverter with low-frequency ripple current reduction on the DC input for an AC photovoltaic module system," IEEE 34th Annu. Power Electron. Spec. Conf. (PESC'02), Vol. 3, pp. 1483-1488, 2002

[14] M. Nagao and K. Harada, "Power flow of photovoltaic system using buck-boost PWM power inverter," Conf. Power Electron. Drive Syst. (PEDS'07), Vol. 1, pp. 144-149, 1997.

[15] F. Harashima, H. Inaba, S. Kondo, and N. Takashima, "Microprocessor- controlled SIT inverter for solar energy system," IEEE Trans. Ind. Electron., Vol. 34, No. 1, pp. 50-55, Feb. 1987. 


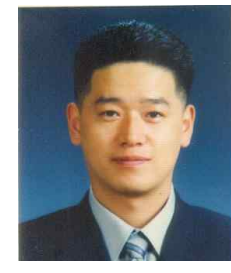

Dong-Kyun Ryu was born in Korea in 1972 . He received his M.S. degree and is currently pursuing his Ph.D. degree in Electrical and Computer Engineering from Sungkyunkwan University, Suwon, Korea, in 2010 and 2014, respectively. He is currently a principal engineer in CDS Power Developement Group-1 of Samsung Electro-Mechanics Co., Ltd., Suwon, Korea. His research interests include DC/DC converters, power factor correction $\mathrm{AC} / \mathrm{DC}$ converters, $\mathrm{DC} / \mathrm{AC}$ inverter, converters and inverters of photovoltaic systems, battery charger systems of electric automobiles, and sever power supply.

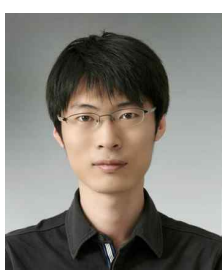

Bong-Yeon Choi was born in Korea in 1987. He received his B.S degree in Electronics and System Engineering from Hanyang University, Ansan, Korea, in 2012. He is currently working toward his Ph.D from the Graduate School of Information and Communication Engineering, Sunkyunkwan University, Suwon. His current research interests include DC/DC converters, inverters, and its control for photovoltaic applications.

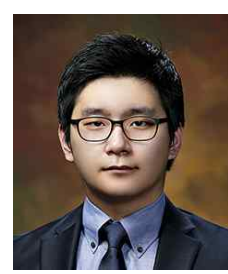

Soon-Ryung Lee was born in Korea in 1987. $\mathrm{He}$ received his B.S. degree in Electrical Engineering from Chungang University, Seoul, Korea, in 2013. He is currently working toward his Ph.D in Electronic Engineering at Sungkyunkwan University. His current research interests include DC/DC converter, battery charger system, and power

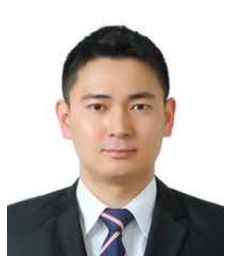

Young-Ho Kim was born in Korea in 1981. $\mathrm{He}$ received his M.S. and Ph.D. degrees in Photovoltaic System and Electrical Engineering from the Sungkyunkwan University, Suwon, Korea, in 2010 and 2014, respectively. $\mathrm{He}$ is currently a senior engineer in the CDS Product Planning Group of Samsung Electro-Mechanics Co., Ltd., Suwon, Korea. His research interests include DC/DC converters, power factor correction $\mathrm{AC} / \mathrm{DC}$ converters, $\mathrm{DC} / \mathrm{AC}$ inverter, converters and inverters of photovoltaic systems, battery charger system of electric automobiles, and sever power supply.

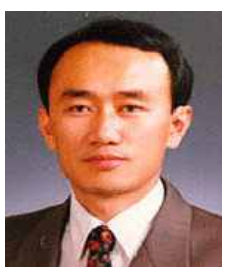

Chung-Yuen Won was born in Korea in 1955. He received his B.S. degree in Electrical Engineering from Sungkyunkwan University, Suwon, Korea, in 1978. He obtained his M.S. and Ph.D. degrees in Electrical Engineering from Seoul National University, Seoul, Korea in 1980 and 1987, respectively. From 1990 to 1991, he worked as a visiting professor in the Department of Electrical Engineering at the University of Tennessee, Knoxville. He has been a member of the faculty of Sungkyunkwan University, where he has been working as a professor in the College of Information and Communication Engineering since 1988. He was also the director of the Samsung Energy Power Research Center. He was the president of the Korean Institute of Power Electronics in 2010. He has been a director of the Korean Federation of Science and Technology Societies since 1988. His current research interests include power electronic of electric machines, electric/hybrid vehicle drives, and power converters for renewable energy systems. 